\title{
Social Signalling as a Non Verbal Behaviour of Teachers in ESL Classroom Interaction
}

\author{
Hema Vanita Kesevan ${ }^{1, *}$, Noor Alhusna Madzlan ${ }^{1}$, Haslinda Hashim² \\ ${ }^{1}$ Faculty of Languages and Communication, Sultan Idris Education University, Malaysia \\ ${ }^{2}$ Faculty of Arts, Computing and Creative Industry, Sultan Idris Education University, Malaysia
}

Received June 11, 2020; Revised August 3, 2020; Accepted August 25, 2020

\begin{abstract}
Cite This Paper in the following Citation Styles
(a): [1] Hema Vanita Kesevan, Noor Alhusna Madzlan, Haslinda Hashim, "Social Signalling as a Non Verbal Behaviour of Teachers in ESL Classroom Interaction," Universal Journal of Educational Research, Vol. 8, No. 11, pp. 5576 - 5580, 2020. DOI: 10.13189/ujer.2020.081161.
\end{abstract}

(b): Hema Vanita Kesevan, Noor Alhusna Madzlan, Haslinda Hashim (2020). Social Signalling as a Non Verbal Behaviour of Teachers in ESL Classroom Interaction. Universal Journal of Educational Research, 8(11), 5576 - 5580. DOI: 10.13189/ujer.2020.081161.

Copyright $\odot 2020$ by authors, all rights reserved. Authors agree that this article remains permanently open access under the terms of the Creative Commons Attribution License 4.0 International License

\begin{abstract}
Non-verbal cues and behaviours are essential aspects of classroom talk, however many studies that were conducted in the field of classroom talk only focused on verbal interaction of teachers' talk and overlooked the importance of non-verbal signalling. The aim of this study is to examine the social signal aspect of teachers' speech in classroom interaction. It particularly investigates the use of non-verbal cues such as facial expressions, bodily gestures and eye contact conveyed by teachers during their classroom lesson, to understand their emotional state and intention. Social signals are chosen as a variable to explore the teachers' classroom interaction as it plays a fundamental role in shaping how messages are delivered to the students in classroom context. Particularly, this study focuses to understand how social signalling shapes the success of teachers' classroom intentions. It is specifically concerned with exploring teachers' non-verbal behaviour and its effectiveness in classroom interaction. This study is beneficial to teachers in understanding their non-verbal cues better to accomplish effective classroom talk.
\end{abstract}

Keywords Social Signalling, ESL, Interaction

\section{Introduction}

Language interaction is not limited only to verbal communication. Non-verbal features such as facial expression, eye contact and bodily gestures are crucial aspects of human spoken interaction. Generally, we can still interpret and make sense the prototypical of behaviours that humans display even though we can't understand the language being spoken (Pentland, 2004). The paralinguistic elements of speech, which are often described as 'non-verbal' behaviour, are a powerful measurement of interaction. A subset of these 'non-verbal' features, the social signalling is frequently underestimated in investigating classroom talk. In a classroom interaction, the quality and success of teachers' talk are determined by both verbal and non-verbal parameters. The meaning conveyed by a teacher does not end with syntactic and semantic content, as often 'what' is said carries as much importance as on 'how' it is actually said. In a classroom context, social signals are the expression of classroom members towards classroom situation and interplay. Social signals are manifested through various non-verbal parameters such as facial expressions, gestures and body postures, and vocal prosody (Pentland, 2004). In a classroom setting, the social signal that a teacher displays both consciously and unconsciously carries meaningful information, for instance expressions inform whether the teacher is confident or doubtful, eye contact notifies tensed or relax state, bodily posture and gestures express the kind of relationship the teacher shares with students. Previous studies focusing on classroom interaction suggest social signalling in the form of non-verbal cues displayed by teachers in classroom as an intentional strategy that 
supports the success of classroom talk. Although it is evident that non-verbal behaviour plays a crucial role in overall communicative process along with verbal communication, past research has paid little attention to the former.

In delivering a message successfully through communication, the non-verbal cues of communication carry two thirds of social meaning in comparison to verbal communication that carries only one third of meaning (Vinciarelli\& Valente, 2010). Irrespective of the fraction attributed to verbal and non-verbal channels in achieving a successful communication, many would agree that non-verbal cues are equally important as verbal meaning for an effective communication. Similarly in a classroom context, the way a teacher displays non-verbal cues plays crucial role to determine the success of classroom interaction. In a context as in Malaysian ESL classroom whereby English is used as a second language and still a foreign language to many in rural part of the country, non-verbal cues used by teachers definitely are deemed important in achieving understanding. The gestures used by teachers such as a simple nod to express an agreement, and hand gestures to indicate turn taking do influence the success of a classroom interaction. Similarly the expression display by students does convey message to a teacher, for instance the puzzled look on a student's face directs the teacher to either repeat or revise immediately. Gumperz (1982) suggest non-verbal cues such as eye contact and facial expressions are time and effort saver.

This study aims to investigate the social signals and its effectiveness in ESL classroom context particularly focusing on three non-verbal aspects; facial expression, eye contact and bodily gestures. It mainly seeks to understand the effectiveness of the non-verbal cues used by teachers from the students' perspectives. The objectives of this study are to:

1. Determine the use of non-verbal cues used by teachers in classroom interaction.

2. Discover if the non-verbal cues used by the teachers' benefit classroom interaction.

\section{Methodology}

\subsection{Context of the Study}

This research was conducted in two secondary level ESL classrooms in a school located in the state of Perak, Malaysia. Two ESL teachers and eighty students of the age 16 from the respective teachers classrooms participated in this study. The students participated in this study possess upper intermediate proficiency level. This study was conducted for a duration of eight weeks to collect two types of data; classroom video recordings and survey questionnaire from the participants. Permission was obtained from education district office and school before this study was conducted. Permission was given to work both with the teachers and students. Consent forms were signed by the participants of this study and the collected data are safely secured to maintain privacy of the participants.

\subsection{Data Collection and Data}

This study adopted a mix method approach of qualitative and quantitative. Two forms of data were collected, which are classroom interaction recordings of two ESL teachers and survey questionnaire from 80 students from the teachers' classroom. Teachers classroom lessons were recorded for a duration of eight weeks, approximately 40 hours of classroom teachings. The recordings were analysed to study teachers' pattern of social signalling. The recordings assisted to determine the use of non-verbal cues; facial expressions, bodily gestures and eye contact used in classroom interaction. Meanwhile the survey questionnaire administrated with students intended to discover the effectiveness of non-verbal cues used by the teachers in their classroom interaction. First the data collected from classroom recordings were analysed to determine the types of non-verbal cues used by the teachers and its usage in the teachers' classroom interaction. Once the pattern was established between the types of non-verbal cues and its usage, the obtained pattern is used to construct items of survey questionnaire. The items of survey questionnaire investigate the effectiveness of the teacher's non-verbal cues in delivering their emotion and intentions towards the success of classroom interaction from the students' perspectives. The qualitative method is used to analyse the classroom recordings, while the quantitative method is used to analyse questionnaire data. The quantitative method includes descriptive statistical testing involving SPSS.

\section{Findings}

The following table shows the results obtained from the classroom recordings and survey questionnaire. The non-verbal signalling depicts the types of non-verbal cues and its usage in the two teachers' classroom interactions meanwhile the numerical percentage represents the students' perspective on the benefits of non-verbal cues in classroom interaction. The findings indicate that the teachers mainly used three types of non-verbal signaling in classroom interactions; facial expression, eye contact and bodily gestures. It further revealed that these non-verbal cues have both positive and negative effect in classroom interaction. Students show greater participation to teachers that smile, display facial expressions while delivering instructions. However they felt difficult to connect with teachers that stare at them and indicate turn taking by using finger. Teachers bodily gestures such as movements in the classroom and frequent eye contact with them contribute to relaxing atmosphere that encourage learning process. 
Table 1. Types of Non-Verbal Signalling and its Effectiveness in Classroom Interaction

\begin{tabular}{|c|c|c|c|c|c|c|c|c|c|}
\hline & Non-Verbal Signalling & \multicolumn{2}{|c|}{ Strongly agree } & \multicolumn{2}{|c|}{ Agree } & \multicolumn{2}{|c|}{ Disagree } & \multicolumn{2}{|c|}{ Strongly disagree } \\
\hline \multicolumn{10}{|c|}{ Facial Expression } \\
\hline \multirow{3}{*}{1} & \multirow{3}{*}{$\begin{array}{l}\text { Smiling teachers encourageeffective } \\
\text { participation than thosewho are always } \\
\text { serious. }\end{array}$} & \multicolumn{2}{|c|}{$24(30 \%)$} & \multicolumn{2}{|c|}{$56(70 \%)$} & \multicolumn{2}{|c|}{ - } & \multicolumn{2}{|c|}{ - } \\
\hline & & M & - & M & 40 & $\mathrm{M}$ & - & M & - \\
\hline & & $\mathrm{F}$ & 24 & $\mathrm{~F}$ & 16 & $\mathrm{~F}$ & - & $\mathrm{F}$ & - \\
\hline \multirow{3}{*}{2} & \multirow{3}{*}{$\begin{array}{l}\text { Teachers facial reaction in classroom talk } \\
\text { influence my understanding towards the } \\
\text { lesson. }\end{array}$} & \multicolumn{2}{|c|}{$56(70 \%)$} & \multicolumn{2}{|c|}{$24(30 \%)$} & \multicolumn{2}{|c|}{-} & \multicolumn{2}{|c|}{-} \\
\hline & & M & 40 & M & 12 & M & & M & \\
\hline & & $\mathrm{F}$ & 16 & $\mathrm{~F}$ & 10 & $\mathrm{~F}$ & & $\mathrm{~F}$ & \\
\hline \multirow{3}{*}{3} & \multirow{3}{*}{$\begin{array}{l}\text { Teachers facial reaction in classroom help } \\
\text { to manage/control students behaviour. }\end{array}$} & \multicolumn{2}{|c|}{$47(58.75 \%)$} & \multicolumn{2}{|c|}{$33(41.25 \%)$} & \multicolumn{2}{|c|}{-} & & \\
\hline & & $\mathrm{M}$ & 16 & M & 9 & M & - & M & - \\
\hline & & $\mathrm{F}$ & 31 & $\mathrm{~F}$ & 24 & $\mathrm{~F}$ & - & $\mathrm{F}$ & - \\
\hline & Eye Contact & & & & & & & & \\
\hline & & & & & & & & & \\
\hline 4 & It is hard to speak in front of those & M & 16 & $\mathrm{M}$ & 14 & $\mathrm{M}$ & - & $\mathrm{M}$ & - \\
\hline & & $\mathrm{F}$ & 31 & $\mathrm{~F}$ & 19 & $\mathrm{~F}$ & - & $\mathrm{F}$ & - \\
\hline & & & & & & & & & \\
\hline 5 & $\begin{array}{l}\text { I avoid eye contacts when I do not know } \\
\text { the answer of the question asked. }\end{array}$ & M & 24 & M & 4 & $\mathrm{M}$ & 5 & M & - \\
\hline & & $\mathrm{F}$ & 42 & $\mathrm{~F}$ & 3 & $\mathrm{~F}$ & 2 & $\mathrm{~F}$ & - \\
\hline & & & & & & & & & \\
\hline 6 & $\begin{array}{l}\text { I pay more attention when the teacher } \\
\text { makes eye contacts with me in the class. }\end{array}$ & M & 24 & M & 4 & M & - & M & - \\
\hline & & $\mathrm{F}$ & 42 & $\mathrm{~F}$ & 10 & $\mathrm{~F}$ & - & $\mathrm{F}$ & - \\
\hline & & & & & & & & & \\
\hline 7 & $\begin{array}{l}\text { Teachers make eye contacts only with the } \\
\text { selected students }\end{array}$ & $\mathrm{M}$ & & M & - & M & 34 & M & 4 \\
\hline & & $\mathrm{F}$ & 3 & $\mathrm{~F}$ & 4 & $\mathrm{~F}$ & 32 & $\mathrm{~F}$ & 3 \\
\hline & & & & & & & & & \\
\hline 8 & $\begin{array}{l}\text { Teachers tend to look away when a } \\
\text { difficult topic is being discussed. }\end{array}$ & M & - & M & - & M & 10 & M & 30 \\
\hline & & $\mathrm{F}$ & - & $\mathrm{F}$ & - & $\mathrm{F}$ & 14 & $\mathrm{~F}$ & 26 \\
\hline & Bodily Gestures & & & & & & & & \\
\hline & The personality and friendly style also & & & & & & & & \\
\hline 9 & contribute to teachers' success and our & $\mathrm{M}$ & 40 & M & - & $\mathrm{M}$ & - & $\mathrm{M}$ & - \\
\hline & learning. & $\mathrm{F}$ & 40 & $\mathrm{~F}$ & - & $\mathrm{F}$ & - & $\mathrm{F}$ & - \\
\hline & I enjoy the lecture of those teachers more & & & & & & & & \\
\hline 10 & who are physically engaged, using hand & $\mathrm{M}$ & 20 & M & - & $\mathrm{M}$ & 10 & M & 10 \\
\hline & gestures while explaining. & $\mathrm{F}$ & 29 & $\mathrm{~F}$ & 5 & $\mathrm{~F}$ & 2 & $\mathrm{~F}$ & 2 \\
\hline & & & & & & & & & \\
\hline 11 & $\begin{array}{l}\text { Teachers movement in the classroom } \\
\text { keeps students active. }\end{array}$ & M & 24 & M & 16 & M & - & M & - \\
\hline & & $\mathrm{F}$ & 40 & $\mathrm{~F}$ & - & $\mathrm{F}$ & - & $\mathrm{F}$ & - \\
\hline & It is easy to speak in front of those & & & & & & & & \\
\hline 12 & teachers who usually encourage students & M & 20 & M & 20 & M & - & M & - \\
\hline & by nodding their head. & $\mathrm{F}$ & 20 & $\mathrm{~F}$ & 20 & $\mathrm{~F}$ & - & $\mathrm{F}$ & - \\
\hline & Students feel nervous and embarrassed & & & & & & & & \\
\hline 13 & $\begin{array}{l}\text { when the teacher indicates (raised finger) } \\
\text { a particular student while asking the }\end{array}$ & $\mathrm{M}$ & 24 & $\mathrm{M}$ & 6 & $\mathrm{M}$ & - & $\mathrm{M}$ & - \\
\hline & question. & $\mathrm{F}$ & 31 & $\mathrm{~F}$ & 9 & $\mathrm{~F}$ & - & $\mathrm{F}$ & - \\
\hline
\end{tabular}

Detailed analysis of the findings revealed that all the students $(100 \%)$ tend to participate in greatly when teachers display positive facial expressions such as smiling. Analysis further showed that the male students' (70\%)understand better when teachers display facial reaction while conducting classroom lessons; however they felt it did not help to control students' behaviour in classroom. Teachers' facial reaction somehow effect the way lesson is delivered and students' participation and understanding but it does not greatly affect teachers' classroom management. Pertaining to eye contact in classroom interaction, the result showed that teachers' eye 
contact influence students' participation and lessons. It has both positive and negative impact towards the students. The students avoided to speak in class when teachers stared at them, in contrary to paying attention to lesson when teachers make eye contact to them. It shows different types of eye contact influence classroom talk and lesson in a different manner. In comparison to male students, the female students $(62 \%)$ felt inferior to participate when were stared and tended to avoid eye contacts $(56 \%)$ when they did not know an answer. However they felt that teacher's eye contact help them to stay focused during the lesson. The findings show that students' gender influence how eye contact is perceived to a certain extend. The male students tend to be less affected although they do not know an answer or when teachers stare at them, it could be related to their nature of masculinity (Christoper, 2002). Pertaining to bodily gestures, all the gestures such as head nodding, hand gestures and physical movements were perceived to give positive impact to the students and their involvement in learning process except for teachers' hand gestures to allocate turns in questioning and answering session. All students $(100 \%)$ were highly inclined towards personality and friendly style of the teachers. They also believed that the way teachers carry themselves enhances their learning process. Although teachers' personality does not contribute to the content knowledge of subject, students $(67.5 \%)$ were motivated to the outlook and sense of humor of teachers. In a similar vein, students $(67.5 \%)$ showed positive involvement towards teachers hand movements during explanation stage, meanwhile $32.5 \%$ did not perceive it as beneficial. This could be related to how much the teachers use hand gestures, heavy usage could lead to confusion (Abercrombie, 1973). Students (90\%) believed that teachers' movement in the classroom kept them active. Teachers' bodily movement do activate students' eye movements as they do follow teachers' movement when they move from a place to another unlike teachers that stand still in front of the classroom. Teachers' head nodding encouraged students (70\%) to speak up during the learning session. As head nodding indicates that teachers attentive to the students as it somehow motivates the students' involvement (Capper, 2002). Both the males $(50 \%)$ and females $(50 \%)$ equally showed agreement with regard to teachers' head node. A vast majority of the students $(58.75 \%)$ felt nervous and embarrassed when the teacher indicated the particular student with their raised fingers, females $(77.5 \%)$ were slightly more demotivated to such teachers than the males. The female students are more influenced than the male students due to the nature of feminine, being modest and delicacy than their male counterpart (Christoper, 2002).

\section{Conclusions}

Non verbal communication is not only crucial in daily life conversation but it has equal importance in classroom interactions. The findings of this study have important implications for the ESL classroom context, its teachers, and students. Based on this study's findings the implications are discussed from the pedagogical point of view and in regard to effective classroom interaction. First, the findings from the video recordings of the teachers classroom interaction revealed that teachers use non-verbal cues mainly for three reasons. Teachers' facial expressions are used to express their emotions, such as smile as a form of approval and frown as a form of disapproval. Meanwhile eye contact is used to establish a connection with a student, for instance looking at a student to get his/her attention and control students' movement in classroom. The teachers use different types of bodily gestures for few reasons; hand movement to provide explanation in terms of lesson content, an open arm to invite participation, thumbs up to show appreciation and thumbs down to indicate an incorrect response. Second, the findings from survey questionnaire indicated that students have mixed reactions towards the use of non-verbal cues in classroom interaction. They perceived certain non-verbal cues such as facial expressions and hand movements to improve understanding towards lessons but did not benefit classroom management such as to control students' discipline. Meanwhile teacher's eye contact proves to both motivate and also makes student to feel inferior to participate in lessons. It can be concluded that the three aspects of non-verbal cues used by teachers, namely facial expressions, eye contact and bodily gestures of the language teachers in their classroom interaction provided more positive impact than negative in achieving teaching and learning goals.

The students mostly perceive teachers' non-verbal cues as a source of motivation, concentration and a tool for maintaining attention. Meaning learning does occur if students' attention is captured as information processing starts with students paying attention to stimuli (Cruickshank et al., 2013). The results of this study indicated that non-verbal cues used by teachers in their classroom interaction effectively influence students' participation in learning process as it increases motivation and makes students feeling comfortable and important. The conducive atmosphere enables them to have self-confidence which leads to greater participation. Thus teachers are encouraged to be aware of social signaling in the form of non-verbal cues and use it in favour of successful teaching and learning process.

\section{Acknowledgements}

We would like to extend our gratitude to the funder of this study, Research Management and Innovative Centre of Sultan Idris Education University that supported this study 
through its University Research Grant project (2018-0219-107-01). We also would like to extend our heartfelt thanks to the teachers and students that contributed in this study.

\section{REFERENCES}

[1] Abercrombie, D. (1973).Paralinguistic communication. In Allen, J.P.B. and Corder S.P. (Ed.), The Edinburgh course in Applied Linguistics (pp. 31-36).

[2] Capper, S. (2000). Non-verbal communication and the second language learner: Some pedagogic considerations. http://www.jalt-publications.org/tlt/.

[3] Christopher,E. (2002).Genderdifferences in non-verbal behavior. Retrieved from http://www.qnselm.edu/internet/ psych/theses/seniors2002/christopher/.html

[4] Cruickshank, D. R. et al., (2003). The Act of Teaching. Boston: McGraw-Hill Companies.

[5] Gumperz, J. J. (1982). Discourse Strategies. Cambridge: Cambridge University Press.

[6] Pentland, A. (2004). Social dynamics: signals and behaviour. $I C D L$, San Diego.

[7] Vinciarelli, A. Valente, F. (2010). Social signal processing: understanding nonverbal communication in social interactions. Proceedings of measuring behaviour. The Netherlands. August 24-27. 